BANGLADESH JOURNAL OF SCIENTIFIC AND INDUSTRIAL RESEARCH

E-mail: bjsir07@gmail.com

\title{
Photoperiod and Relationship with Body Mass and Size in Bumblebee, Bombus ter- restris L. (Hymenoptera: Apidae) Workers
}

\author{
M. R. Amin ${ }^{a *}$ and Y. J. Kwon ${ }^{b}$ \\ ${ }^{a}$ Department of Entomology, Hajee Mohammad Danesh Science and Technology University, Dinajpur 5200, \\ Bangladesh and ${ }^{b}$ Department of Agricultural Biology, Kyungpook National University, \\ Daegu 702-701, Korea Republic
}

\begin{abstract}
Bombus terrestris L. appears to be a promising and cosmopolitan bumblebee species for pollination of greenhouse crops and its demand for large scale rearing. For effective crop pollination, colonies with optimal body sized workers are essential because generally larger bees visit more flowers per unit time. The body size is correlated with flexible development and growth in a changing environment. This study explored the effect of different photoperiodic regimes i.e., L0:D24, L8:D16, L16:D8 and L24:D0 in regulation of the body mass and size of bumblebee workers during the stages of larval, pupal and adult eclosion. The results showed that wet masses of larvae, pupae and adult ranged from $144.2 \pm 7.6$ to $198.7 \pm 11.7,398.3 \pm 16.0$ to $464.7 \pm 9.3$ and $224.8 \pm 9.3$ to $274.7 \pm 7.0 \mathrm{mg}$, respectively whereas their dry masses were $47.7 \pm 4.8$ to $63.7 \pm 5.4,176.7 \pm 6.7$ to $204.7 \pm 5.6$ and $62.8 \pm 3.0$ to $78.7 \pm 2.1 \mathrm{mg}$, respectively. The length of wing and tibae were observed $8.14 \pm 0.82$ to $8.47 \pm 0.73$ and $4.30 \pm 0.51$ to $4.47 \pm 0.32 \mathrm{~mm}$, respectively. The L0:D24 photoperiodic condition produced heavier larvae, pupae and adult workers with larger wings and tibiae and worker's body size and mass decreased significantly when the bees were reared under L16:D8 and L24:D0 conditions.
\end{abstract}

Key words: Bumblebee, Body mass and size, Photoperiod

\section{Introduction}

Bumblebees are primitively eusocial bees which possessed approximately 300 species and mostly available in the temperate regions of the world (Prys-Jones and Corbet 1991). Among the bumblebee species Bombus terrestris L. (Hymenoptera: Apidae) has been shipped throughout the world in vast numbers for pollinaton of glasshouse crops (Goka et al., 2001). The colony of $B$. terrestris is established by a single queen early in the spring. After emergence from hibernation queens expose to daylight look for a suitable site to form a colony. During this period, they feed their first batch of larvae and then the first workers appear (Tasei and Aupinel 1994). Several authors reported rearing of bumblebee queens in the dark (Van Heemert et al., 1990; Asada and Ono 2000) whereas Tasei and Aupinel (1994) stated that light regimes have significant effect on the oviposition and sexual production of $B$. terrestris.

Bumblebees exhibit an approximately 10 -fold variation in mass within the worker caste developed in a same nest (Goulson et al., 2002). Larger workers have a higher rate and speed of foraging activity for nectar and pollen (Spaethe and Weidenmueller 2002). They can efficiently exploit a range of different sizes of flowers (Peat et al., 2005). Body mass of bee is a measure of size and it is correlated with forewing length (Bullock 1999). Photoperiods determine the developmental period and growth rate of insects and thus the size and weight can be affected by photoperiod (Musolin and Saulich 1997). The developmental period and size variation due to the effect of photoperiod have clearly shown in crickets (Mousseau and Roff 1989). Individuals reared under late photoperiod had decreased age and size at emergence (Johansson et al., 2001; De Block and Stocks 2003). But no comparative experiments of artificial light effect on the bumblebee body mass and size variation have been reported. Therefore, this study was under taken to quantify the effect of four photoperiodic regimes on the body mass and size variation of $B$. terrestris under laboratory conditions.

\section{Materials and Methods}

\section{Collection and rearing of insect}

$B$. terrestris queens which had artificially overwintered in meshed peat in a refrigerator at $4^{\circ} \mathrm{C}$ temperature and $80 \%$

\footnotetext{
*Corresponding author. E-mail: ruhul_hstu@yahoo.com
} 
moisture content were collected from the mass rearing system of the Department of Agricultural Biology, Kyungpook National University, Daegu, Korea. The experiment was done at the same laboratory during July 2004 to June 2006. The overwintered queens were introduced into flight cages $(40 \times 40 \times 60 \mathrm{~cm})$ having illumination facility and provided with ad libitum frozen pollen grain of Actinidia arguta (Plench) and sugar solutions (1.5:1, w/v). The cages were kept for one week in a separate Growth Chamber maintained at $28 \pm 1{ }^{\circ} \mathrm{C}, 50 \pm 5 \% \mathrm{RH}$ and photoperiodic regimes of L0:D24, L8:D16, L16:D8 and L24:D0 conditions. Photoperiodic treatments were scheduled with $220 / 240 \mathrm{~V}$ fluorescent white light $(40 \mathrm{~Hz}, \lambda: 0.96-0.17 \mathrm{~nm})$ at an intensity of 700 lux on the floor of flight cages and rearing boxes. The intensity of light was measured with a digital lux meter and the photophase was regulated with timer.

After one week, queens were isolated for oviposition in small transparent plastic boxes $(16 \times 11 \times 7 \mathrm{~cm})$. The boxes were provided with ample frozen pollen grain in a $4 \mathrm{~cm}$ diameter petri dish and sugar solution $(1.5: 1, \mathrm{w} / \mathrm{v})$ in a perforated plastic tube. To stimulate oviposition, 1-2 day old frozen queen pupa and one anaesthetized B. terrestris worker were provided to each rearing box. The rearing boxes were kept in the respective photoperiodic chamber. When the queen laid eggs, the anaesthetized worker was removed from that rearing box. The boxes were kept in those conditions until the workers of the first brood cells were emerged. For further development, the colonies were shifted to larger colony boxes $(27 \times 18 \times 13 \mathrm{~cm})$ which were connected with sugar tanks $(30 \times 20 \times 4 \mathrm{~cm})$ by cotton filter. The colonies completed their development successfully in their respective growth chambers. In the colonies, bees were fed with frozen pollen bar prepared from $50 \%$ honey solution and fresh pollen powder and unlimited amounts of sugar solutions $(1.5: 1, \mathrm{w} / \mathrm{v})$.

\section{Measurement of body mass and size}

Body mass of worker was measured when 50 - 60 workers were developed in a colony. In each photoperiodic treatment, 60 individuals from each category were randomly selected and weighed. A maximum of 10 individuals were sampled from each colony. A digital Top Loader Balance (ModelMW120; Casbee, Samsung, Korea) to an accuracy of $0.01 \mathrm{~g}$ was used for measurement of body mass. Live weight of each adult bumblebee was measured at the 1st day of its emergence. Full grown larvae without a shell and 1- to 2day-old pupae including their shell were considered to meas- ure their masses. For the measurement of dry weight, all the individuals were dried in an incubator at $60{ }^{\circ} \mathrm{C}$ for one week and weighed. The length of wings and tibiae were measured in units of $0.04 \mathrm{~mm}$ using Motic Images Plus 2.0 Digital Microscopy Software.

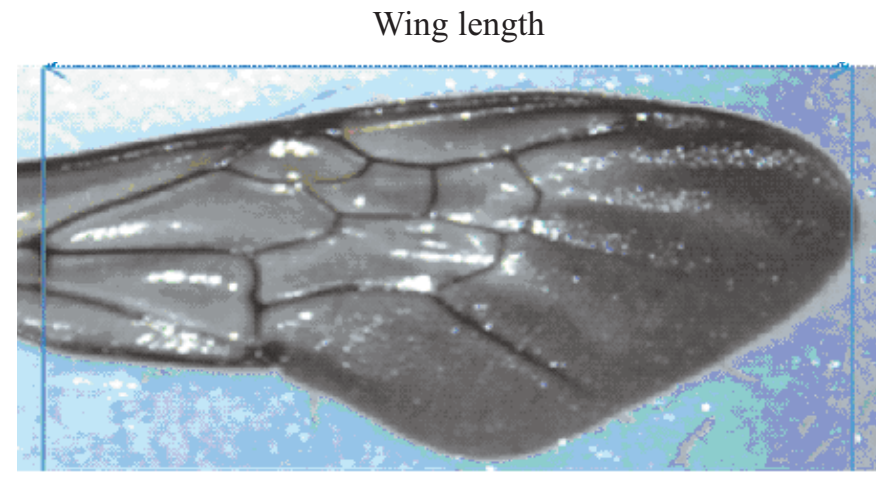

Fig. 1: Mesurement of wing length

tibiae length.

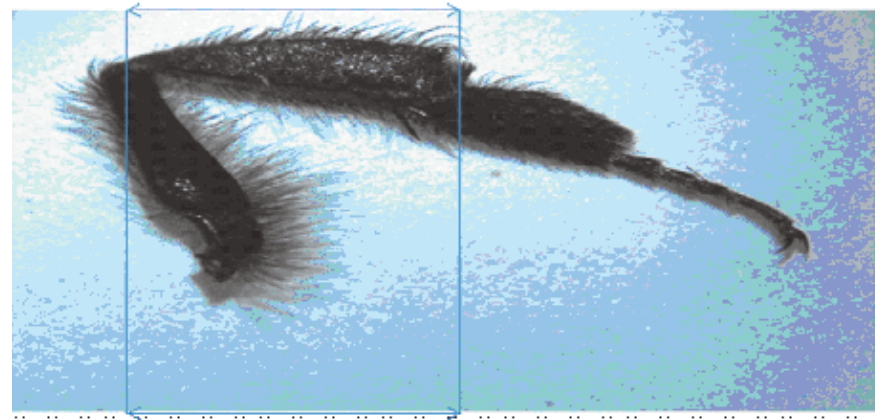

Fig. 2: Mesurement of tibiae length

\section{Statistical analysis}

Data were analysed by analysis of variance (ANOVA) and the mean values were separated by Duncan's multiple range test (DMRT). All analyses were performed by using SPSS Statistics (PASW 17 software).

\section{Results and Discussion}

Figure 3 shows that photoperiodic regimes have significant effect on the wet and dry masses of $B$. terrestris worker larvae (wet mass: $\mathrm{F}_{3}, 236=5.8, \mathrm{p}<0.001$; dry mass: $\mathrm{F}_{3}, 236=$ $3.6, \mathrm{p}<0.05)$. Larval wet masses ranged from $144.2 \pm 7.6$ to $198.7 \pm 11.7 \mathrm{mg}$ and the larvae that were reared under L0:D24 condition revealed significantly the highest mass. The dry masses of larvae varied from $47.7 \pm 4.8$ to $63.7 \pm 5.4$ $\mathrm{mg}$. The larvae showed highest dry masses when they were reared under L0:D24 photoperiodic condition and a statisti 


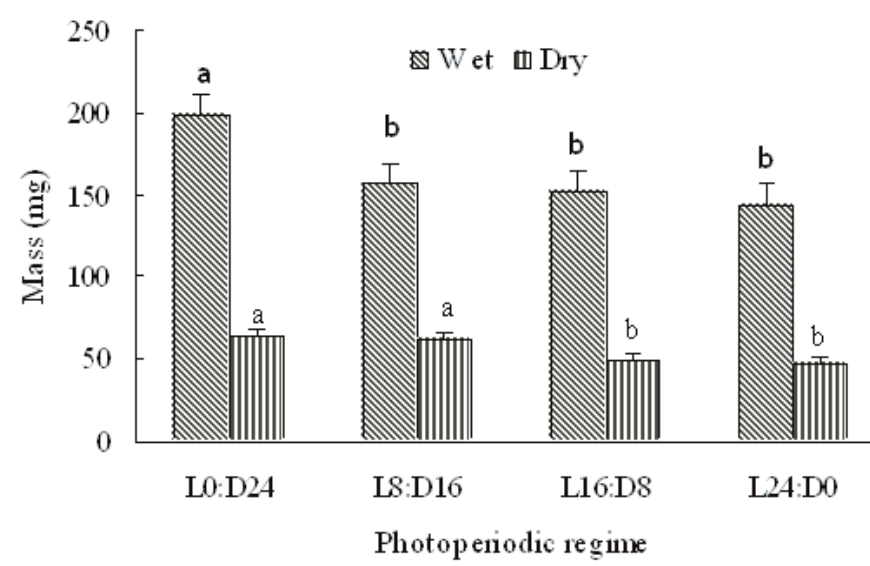

Fig. 3: Photoperiodic influences on the body mass (Mean \pm S.E.) of Bombus terrestris worker larvae. Bars with no common letter are significantly different ( $p$ $\leq \mathbf{0 . 0 5}$, DMRT). $\mathbf{N}=\mathbf{6 0}$ larvae in each treatment.

cally identical result was observed at L8:D16 condition. Photoperiods showed significant effect on the pupal wet $\left(\mathrm{F}_{3,236}=6.4, \mathrm{p}<0.001\right)$ and dry $\left(\mathrm{F}_{3,236}=7.0, \mathrm{p}<0.001\right)$ mass (Fig. 4). The pupal wet masses varied from $398.3 \pm$ 16.0 to $464.7 \pm 9.3 \mathrm{mg}$ and dry masses from $176.7 \pm 6.7$ to $204.7 \pm 5.6 \mathrm{mg}$. Pupae reared under L0:D24 photoperiodic condition showed the highest wet and dry mass whereas the pupae reared under L24:D0 photoperiodic treatment showed lowest wet and dry mass. Photoperiodic influences on the body mass of adult $B$. terrestris worker on the day of emergence are shown in figure 5. Highest wet and dry mass of worker

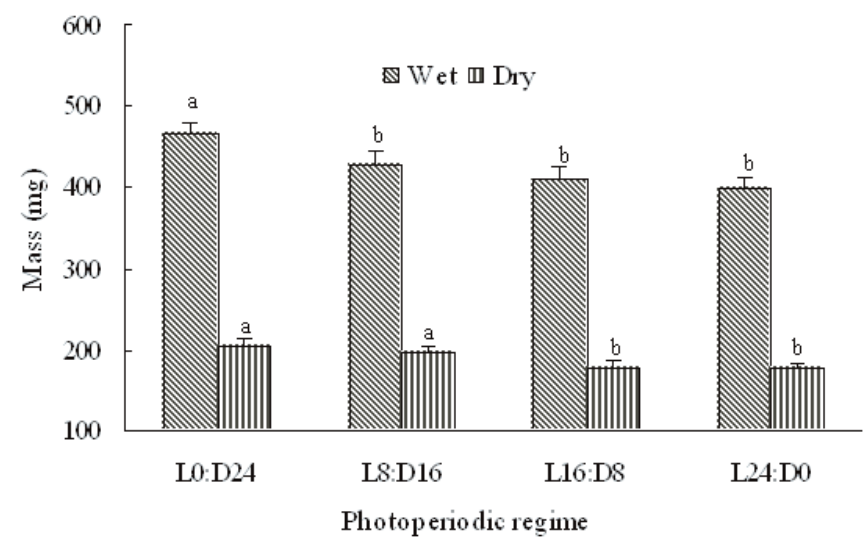

Fig. 4: Photoperiodic influences on the body mass (Mean \pm S.E.) of Bombus terrestris worker pupae. Bars with no common letter are significantly different $(p \leq$ 0.05, DMRT). $\mathrm{N}=60$ pupae in each treatment

(274.7 \pm 7.0 and $78.7 \pm 2.1 \mathrm{mg}$, respectively) was recorded under L0:D24 conditions, whereas the lowest wet and dry mass $(224.8 \pm 9.3$ and $62.8 \pm 3.0 \mathrm{mg}$, respectively) was found under L24:D0 treatment. ANOVA for the worker showed significant differences in wet and dry masses (wet mass: $\mathrm{F}_{3,236}=9.0, \mathrm{p}<0.0001$; dry mass: $\mathrm{F}_{3,236}=10.7, \mathrm{p}<$ $0.0001)$. Table I shows that wing length of $B$. terrestris worker varied with different photoperiodic rigimes $\left(\mathrm{F}_{3,236}=2.66\right.$, $\mathrm{p}<0.05$ ) and wing lengths varied from $8.14 \pm 0.82$ to $8.47 \pm$ $0.73 \mathrm{~mm}$. The highest length of wing was noticed to the workers that were reared under L0:D24 condition. Significant difference existed $\left(\mathrm{F}_{3,236}=2.88, \mathrm{p}<0.05\right)$ in tibiae length of workers with photoperiodic regimes (Table I). Tibiae lengths varied from $4.30 \pm 0.51$ to $4.47 \pm 0.32 \mathrm{~mm}$ and the workers that were reared under L0:D24 condition exhibited the highest tibiae length.

The results showed that photoperiods have a profound influence on the body mass of $B$. terrestris workers at the stages of larval, pupal and adult eclosion. Body masses decreased with increasing length of photoperiods. In all the treatments, heavier larvae, pupae and adults were distinctly encountered

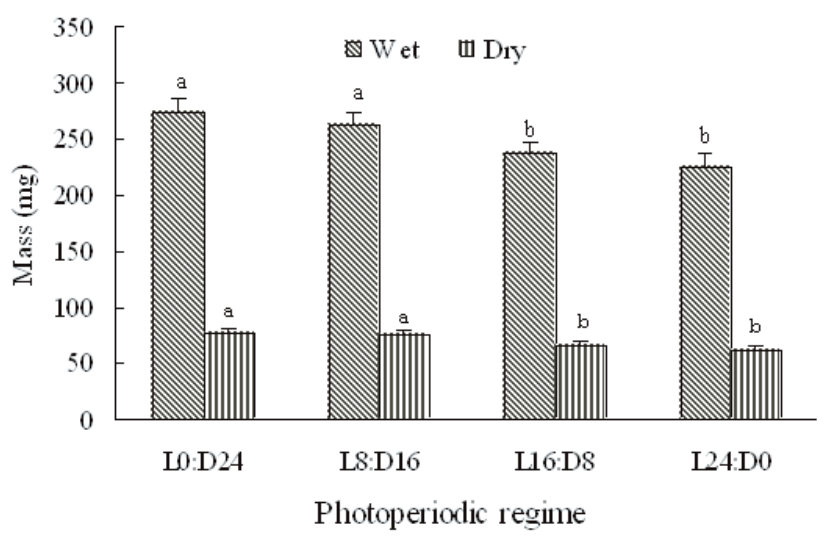

Fig. 5: Photoperiodic influences on the body mass (Mean \pm S.E.) of Bombus terrestris worker on the 1st day of eclosion. Bars with no common letter are significantly different $(p \leq 0.05$, DMRT $) . \quad N=60$ adult in each treatment

under L0:D24 condition. The adult body mass decreased significantly when the colonies were developed under L16:D8 and L24:D0 conditions. Wings and tibial length also showed a similar trend with the duration of photoperiod. Blanckenhorn (1997) observed that photoperiod influenced the growth rate, development period and size of yellow dung fly. Nakamura (2002) reported that the size of the pentatomid bug, Dolycoris baccarum was greatly influenced by intermediate temperature under the long-day photoperiod whereas the size of the adults increased with higher temperature during short day photoperiod. Age and size of the damsel fly, Lestes viridis was decreased at higher temperatures and at lower photoperiod (De Block and Stoks 2003). These earlier investigations suggest that insects optimize their size through flexible development and growth in a changing environment which is in harmony with our find 
Table. I: Photoperiodic influences on the wing and tibia length (Mean \pm S.D.) of Bombus terrestris worker on the 1st day of eclosion

\begin{tabular}{l|c|c|c|c}
\hline \multirow{2}{*}{ Length $(\mathrm{mm})$} & \multicolumn{4}{|c}{ Photoperiodic regimes } \\
\cline { 2 - 5 } & L0:D24 & L8:D16 & L16:D8 & L24:D0 \\
\hline Wing & $8.47 \pm 0.73 \mathrm{a}$ & $8.45 \pm 0.72 \mathrm{a}$ & $8.21 \pm 0.83 \mathrm{ab}$ & $8.14 \pm 0.82 \mathrm{~b}$ \\
Tibae & $4.47 \pm 0.32 \mathrm{a}$ & $4.47 \pm 0.35 \mathrm{a}$ & $4.32 \pm 0.46 \mathrm{ab}$ & $4.30 \pm 0.51 \mathrm{~b}$ \\
\hline
\end{tabular}

Bars with no common letter are significantly different $(p=0.05$, DMRT). $\mathrm{N}=60$ adult in each treatment

ings. Mishra and Omkar (2005) reported that continuous light has a negative effect on physiological function of the ladybird, $P$. dissecta and resulted in poor development. Grinfeld and Zacharova (1971) found that photoperiods significantly hampered the production of bigger worker which is in agreement with our findings. Bees' compound eyes act as photoreceptors in different photoperiods and have great influence on the morphometrics. Optimal-sized workers are very important for colony growth, reproductive rates and potential pollination. Therefore, outcome of this study may draw attention to the bumblebee breeders.

\section{References}

Asada S. and Ono M. (2000). Difference in colony development of two Japanese bumble bee, Bombus hypocrita and Bombus ignitus (Hymenoptera: Apidae). Appl. Ent. Zool. 35: 597-603.

Blanckenhorn W. U. (1997). Effects of temperature on growth, development and diapause in the yellow dung fly-against all the rules? Oecologia. 111: 318-324.

Bullock S. H. (1999). Relationships among body size, wing size and mass in bees from a tropical dry forest in Mexico. J. Kan. Ent. Soc. 72: 426-439.

De-Block M.and Stocks R. (2003). Adaptive sex-specific life history plasticity to temperature and photoperiod in a damselfly. J. Evol. Biol. 16: 986-995.

Dimetry N. Z. (1988). Ecology and effectiveness of Aphidophaga. Acad. Publ., The Hague. pp.135-140.

Goka K., Okabe K., Yoneda Y. and Niwa, S. (2001). Bumblebee commercialization will cause worldwide migration of parasitic mites. Mol. Ecol. 10: 2095-2099.

Goulson D., Peat J., Stout J. C., Tucker J., Darvill B. and Derwent L. C. B. (2002). Can alloethism in workers of the bumblebee Bombus terrestris be explained in terms of foraging efficiency? Anim. Behav. 64: 123-130.

Grinfeld E. K. and Zacharova L. V. (1971). The role of photoperiodism in the development cycle of bumblebee (Hymenoptrea: Bombidae). Vestnik Leningradskogo
Gosudarstvennogo Universiteta (Biologii). 9: 149-150.

Johansson F., Stoks R., Rowe L. and De-Block, M. (2001) Life history plasticity in a damselfly: effects of combined time and biotic constraints. Ecology. 82: 1857-1869.

Mishra G. Omkar (2005). Influence of components of light on the life attributes of an aphidophagous ladybird, Propylea dissecta (Coleoptera: Coccinellidae). Int. J. Trop. Insect Sci. 25: 32-38.

Mousseau T. A. and Roff D. A. (1989). Adaptation to seasonality in a cricket: patterns of phenotypic and genotypic variation in body size and diapause expression along a cline in season length. Evolution. 43: 1483-1496.

Musolin D. L. and Saulich A. K. (1997) .Photoperiodic control of nymphal growth in true bugs (Heteroptera). Ent. Rev. 77: 768-780.

Nakamura K. (2002). Effect of photoperiod on the size-temperature relationship in a pentatomid bug, Dolycoris baccarum. J. Therm. Biol. 27: 541-546.

Peat J., Tucker J. and Goulson D. (2005). Does intraspecific size variation in bumblebees allow colonies to efficiently exploit different flowers? Ecol. Entomol. 30: 176-181.

Pry-Jones O. E. and Corbet S. A. (1991). Bumblebees. Second edition, Richmond Publishing, Slough, UK.

Spaethe J. and Weidenmueller A. (2002). Size variation and foraging rate in bumblebees (Bombus terrestris). Insect. Soc. 49: 142-146.

Tasei J. N. and Aupinel P. (1994). Effect of photoperiodic regimes on the oviposition of artificially overwintered Bombus terrestris L. queens and the production of sexuals. J. Apic. Res. 33: 27-33.

Van Heemert C., De-Ruijter A., Van den Eijnde J., Van der and Steen J. (1990) Year-round production of bumble bee colonies for crop pollination. Bee World. 71: 54-56.

Received : March, 16, 2010;

Accepted : March 11, 2011 